\title{
Impact of Social risk, Government and Psychological Factors with Moderator Cultural Factors on Online Shopping Behavior in Pakistan
}

\author{
Anam Bhatti ${ }^{1}$, Shafique Ur Rehman ${ }^{2}$ \\ ${ }^{1,2} \mathrm{Ph}$.D. Scholar Universiti Utara Malaysia \\ Email: gujranwalaanam091@gmail.com, shafiqueurrehman2018@gmail.com
}

\begin{abstract}
The objective of the current study is to examine the impact of social risk, government role, and psychological factors on online shopping behavior. In addition, the moderating role of culture between social risk and online shopping behavior. Simple random sampling technique was used to collect data from respondents by using a questionnaire approach. Confirmatory factor analyses, as well as structural equation modelling techniques, were used for analysis purpose. Findings revealed that social risk and psychological factors have a negative and significant impact on online shopping behavior. Government role and culture have a positive and significant impact on online shopping behavior. Moreover, culture positively moderates the relationship between social risk and online shopping behavior. Between social risk and online shopping behavior moderating role of culture have less attention in prior studies and this research fills that gap. Future research should be held in some other developing countries as well as in developed countries with financial risk, product risk, privacy risk, convenience risk, electronic word of mouth, brand association, advertising factors, perceived quality, and online shopping behavior.
\end{abstract}

Keywords: Social Risk, Psychological Factors, Government Role, Culture, Online Shopping Behavior

\section{Introduction}

The internet changed the human life by its easiness to use, internet becoming most popular and irreplaceable in our life due to the internet we are connected with each other like a family, the internet also makes our life much easy and fast. Online shopping has become very important in daily life due to the internet. In Pakistan culture is collectivist and people prefer to buy with family or in groups so, we are concerned about family and friends opinion about our choice (Aijaz \& Butt, 2009). Pakistan's government realized this opportunity to took initiatives for e-commerce as early as 2000 (Khan \& Arshad, 2010). Psychological 
factors influence customers' behavior to buy online and potential loss of self- esteem by not getting the right product (Almousa, 2011; Candra \& Iahad, 2013). Cultural play major role in behavior some time due to culture some policies not applicable and sometimes culture become supportive to launch a new system and in Pakistan people like to buy face to face conversation (Oluyinka, Shamsuddin, Wahab, Ajagbe, \& Enegbuma, 2013). The main purpose of this study is to examine the impact of social risk, government role and psychological factors online shopping behavior. Moreover, determines the moderating role of cultural factors between social risk and online shopping behavior. There are many factors social risk, government role, and psychological factors, cultural factors effect on online shopping behavior. There is a need to study online shopping behavior in developing countries (Bhatti, 2018; Bhatti, Saad, \& Gbadebo, 2018). Research Questions are (1) What are the influences of social risk, psychological factors, and government role on online shopping behavior? (2) Is culture moderate between social risk and online shopping behavior?

\section{Literature Review and Hypothesis Development}

\section{A. Social risk}

Pakistani culture is collectivist so, people have concerned about others 'opinion, they concern about friends, family, and colleagues regarding their own activities and actions and people encourage or discourage them for their actions (Aijaz \& Butt, 2009; Nasir, Wu, Yago, $\& \mathrm{Li}, 2015)$. Social risk is the perception of consumer that purchased product disapprove from family and friends and loss of status in a social group by choosing an inappropriate product from the inappropriate channel (Li \& Zhang, 2002; Popli \& Mishra, 2015). Furthermore, social risk loses the confidence of the people, self-esteem about product (Amin \& Mahasan, 2014). Moreover in social group family member highly affect online shopping behavior and sometimes one family affect other family living in society usually, friends play important role in shopping behavior (Philip Kotler \& Armstrong, 2010). Social risk negative influence on online shopping behavior and people avoid online shopping (Khan-SZABIST \& Arshad-SZABIST, 2010; Qureshi, Fatima, \& Sarwar, 2014; Rind et al., 2017). Furthermore, several studies show that there is significant relationship between social risk and online shopping behavior (Almousa, 2014). In addition, some studies show an insignificant relation between social risk and online shopping behavior (Masoud, 2013; Zhang, Tan, Xu, \& Tan, 2012). Hence need to introduce another variable culture between social risk and online shopping behavior as a moderator. 
Pakistan Journal of Humanities and Social Sciences, 7(1), 2019

H1: Social risk has a significant and negative impact on online shopping behavior

H2: Cultural moderate the relationship between social risk and online shopping behavior

\section{B. Government Role}

Government is the group of people with power and authority to govern country, every country have their own government who perform specific functions establish justice, approve budget etc. government promote business in country by taking initiatives and facilitate by making policies for them Scouting/BSA (21 March 2018) but in Pakistan case its different, unfortunately, Pakistan' government is reactive than proactive in nature and 95\% Pakistani economy is undocumented and informal (Aijaz \& Butt, 2009). In Pakistan e-commerce start in 2000 and in 2001 Pakistani government took some initiatives and provide Provision of funds for software companies so they get ISO 9000 and CMM certification, foreign investors have 100\% ownership of equity in IT, Tax is exempted for IT companies till 2016, 100\% repatriation of profits by IT companies, State bank of Pakistan allowed the opening of internet merchant's accounts by bank and wanted to convert government to e-government but failed because government could not take steps to improve e-commerce structure furthermore, government provide only a few websites which currently have dynamic application no more improvement in websites and infrastructure, there is no exact figure of GDP e-commerce but only $0.2 \%$ of GDP in R\&D sector in Pakistan Shahid (March 10, 2016). Government failed to give safe e-commerce environment in country because over the last decade government of Pakistan is unable to hold law strongly as well as unable to improve education specially IT education unfortunately less than 1\% people are internet literate in Pakistan Aijaz and Butt (2009) and overall literacy rate of also drop 60 to 58\% Yusufzai (2018). Meanwhile, there is no security for online transactions websites frequently hacked hence, these factors negatively affect consumer online shopping behavior and they avoid to buy e-commerce in Pakistan is still on early stage (Aijaz \& Butt, 2009). There is a significant relationship between Government and online shopping (Akhlaq \& Ahmed, 2015).

H3: Government has a significant and positive impact on online shopping behavior

\section{Psychological risk}

Self-motivation, perception, learning, belief as well as attitude are psychological factors (Rani, 2014). Motivation is defined as needs that must be met, these needs can be biological and psychological such as discomfort, hunger, belonging and self-esteem (Philip Kotler \& Armstrong, 2010). Perception is defined as inferring physical feelings like sights, noises, and smells, every person has a different perception than others and different buying 
behavior (Ricciuto, Tarasuk, \& Yatchew, 2006). Learning is an experience through which online consumer behavior change (Philip Kotler \& Armstrong, 2010). Furthermore in online shopping consumer disclose their personal details like name, address, credit card details so in this case, psychological factors such as privacy issue, misuse of personal information and trust affect consumer online shopping behavior (Lee \& Huddleston, 2009; Nazir, Tayyab, Sajid, Rashid, \& Javed, 2012). Psychological factors negatively affect consumer buying behavior because of consumer not secure in online payment hence, they avoid online shopping (Almousa, 2014; Y.-H. Chen, Hsu, \& Lin, 2010). Meanwhile, different studies proved that psychological factors have strong relation with online shopping behavior (Adnan, 2014). Psychological factors potential loss of self- esteem by not getting the right product (Almousa, 2011; Candra \& Iahad, 2013). Some previous studies reveal that there is significant relation between psychological factors and online shopping behavior (leyiaro, 2015; Nazir et al., 2012).

H4: Psychological factors have a significant and negative impact on online shopping behavior

\section{Cultural}

Cultural is a group of some values including roles, behavior, customs, belief, and traditions shared with people in specific society (Tanner \& Raymond, 2012). Culture learned from common habits and behavior among a specific group of people that living together (Little et al., 2012). Furthermore cultural is a social heritage of a society in which pattern of style develop or discovered by interacting people and handle the problem which arises from cultural like trust, knowledge, language barrier and practices pass on to new people by teaching or engagement. Meanwhile, the culture of any society influence consumer behavior (Phillip Kotler \& Keller, 2006). Consumer behavior consists of some values and beliefs that affect their behavior and purchase decision (Armstrong, Adam, Denize, \& Kotler, 2014). In addition, people living in developing countries prefer to buy face to face, so technology is much destructive in this culture (Oluyinka et al., 2013). Furthermore, some more issues which affect in online shopping such as language problem English require for IT use and online shopping but every culture have their own language similarly in Pakistan people also face language problem and avoid online shopping because they could not understand English and unable to the operate computer. Previous studies show a significant relation between cultural and online shopping (Kanoti, 2017).

H5: Cultural factors have a significant and positive impact on online shopping behavior 
Figure 1: Theoretical Framework

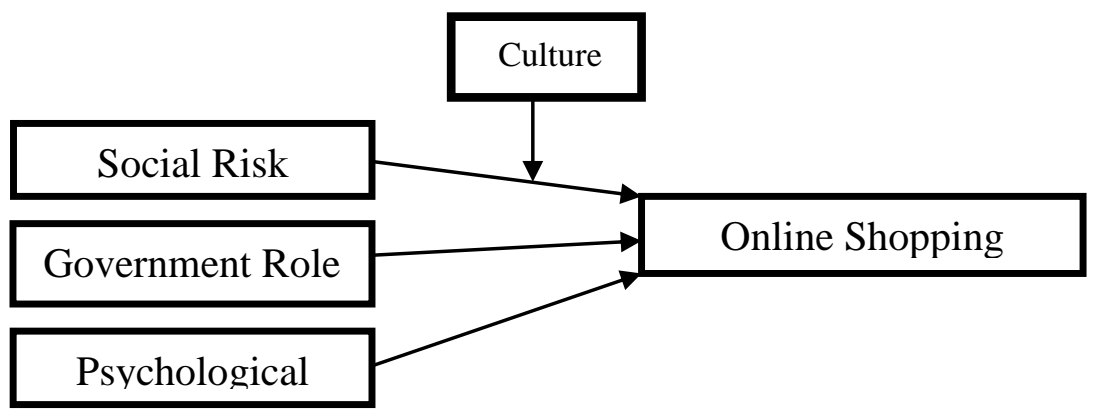

\section{Research Methodology}

The current study is descriptive in nature, in 1994, Creswell told that descriptive researches are those researches, in which existing situation described instead of interpreting and making judgments. This kind of research provides information about the existing situation and scenario by focusing on the past or present. Moreover, this study is quantitative and convenience sampling technique uses to collect data from respondents and data collected from 130 respondents who buying online shopping behavior in Lahore, Gujranwala, Islamabad and questionnaires distributed among respondents. These cities select for data collection because our respondents are those that have awareness from internet technology and recognize how an online transaction perform and in these cities education level higher. Various prior studies used to build a questionnaire of this study. Social risk measured by using 04 items that were adopted from (Masoud, 2013), government role measured by using 5 items and adopted from (C.-C. Chen, Chen, \& Tung, 2018), psychological risk measured by using 4 items and adopted from (Bhukya \& Singh, 2015), culture measures by using 05 items and adopted from (Park, Rehg, \& Lee, 2005), and online shopping behavior consists eight measures and adopted from (Masoud, 2013). First instruments adopted and after that distributed among respondents that shop online on 5-Likert scales that range 1 to 5 . 1 represents (strongly disagree) and 5 represents (strongly agree).

\section{Results and discussion}

\section{A. Demographic Profile}

From 130 respondents that filled questionnaire 94 (72\%) represents female and 36 (28\%) represents the male. Regarding the age of respondents, $66(50.76 \%)$ belongs equal or less than 25 years. $32(24.61 \%)$ were within 26 to 30 years, 28 (21.53\%) respondents were within 31 to 35 years, and the remaining $4(0.03 \%)$ were more than 35 years. In this study, females are greater than males because we distribute 300 questionnaires equally to males and 
females. Out of 250 questionnaires, 125 send to males and remaining questionnaires send to females but female response rate higher than males. In the current study, most of the respondents did a master degree and represents 76 (58.46\%) that followed bachelor degree holders that represent 46 (35.38\%), and 8 respondents were doing M.Phil and Ph.D. degree.

\section{B. Reliability Test}

After demographic analysis calculates reliability test of variables such as social risk, government role, psychological factors, culture, and online shopping behavior. Reliability test conducted to know that data that we are using in this study reliable or not for analysis. Cronbach's alpha calculated to know data reliability. The value of Cronbach's alpha must be equal to 0.70 or greater than this value (Nunnally, 1978). Below in Table 1 the value of Cronbach's alpha mentioned.

Table 1: Reliability Results

\begin{tabular}{|c|c|c|}
\hline Variables & Items & Cronbach's Alpha \\
\hline Social risk & 04 & 0.824 \\
\hline Government role & 05 & 0.782 \\
\hline Psychological risk & 04 & 0.814 \\
\hline Culture & 05 & 0.769 \\
\hline Online shopping behavior & 08 & 0.772 \\
\hline
\end{tabular}

As the above table shows that social risk, government role, psychological risk, culture, and online shopping behavior having Cronbach's alpha more than standardized value as suggested by (Nunnally, 1978). Therefore, the reliability requirement achieved and data available for further analysis.

\section{Normality Test}

Normality test is the second requirement after the reliability test. Normality test conducted to know that our data is normal or not. In normality test, we see two things like Kurtosis and Skewness (Meyers, Gamst, \& Guarino, 2016). According to Meyers et al. (2016), kurtosis range must be between \pm 3.0 and skewness range must be between \pm 1.0 . In this study, our data fulfils these two conditions and skewness and kurtosis values within the standardized range. Hence, data fulfill the requirement of normality test and can be used for further analysis.

\section{Confirmatory factor analysis (CFA)}

To carry out CFA current study estimated the measurement model and evaluates factor loadings of variables items. Convergent validity of the items calculated by using three things such as factor loadings, average variance extract (AVE), and composite reliability 
(CR). The validity of the items of the particular variables convergent in that case when factor loadings are equals to or greater than 0.50 (Hair, Ringle, \& Sarstedt, 2011). In this study, social risk minimum factor loading 0.589 and maximum factor loading 0.769 . Moreover, government role factor loading within the range of 0.625 to 0.809 . Furthermore, psychological factors minimum value of factor loading is 0.547 and maximum factor loading is 0.819 . Meanwhile, the factor loading range of culture is 0.569 to 0.815 . Additionally, factor loading range of online shopping behavior is 0.648 to 0.759 . Therefore, in current study data fulfil the requirement of factor loading and all items loading are greater than 0.50. AVE values of social risk, government role, psychological factors, culture, and online shopping behavior are $0.523,0.510,0.565,0.558$, and 0.523 respectively. Therefore, our data meets the criteria of AVE that values of all items must be greater than 0.50. CR values of social risk, government role, psychological factors, culture, and online shopping behavior are 0.927, $0.816,0.853,0.913$, and 0.897 respectively. Hence, CR criteria meet and all values of items higher than 0.80 .

\section{E. Descriptive \& Correlation Analysis}

In this section, we discussed descriptive \& correlation analysis. Table 2 shows descriptive and correlation analysis. Results revealed that all constructs are significantly correlated. Correlation table shows that social risk is highly significantly correlated with online shopping behavior ( $\mathrm{r}=.831, \mathrm{p}<.01)$. In mean column social risk and government factors near to satisfied value that is 4 . Remaining variables mean value more than satisfied value.

Table 2: Descriptive \& correlations analysis

\begin{tabular}{|c|l|l|l|l|l|l|l|}
\hline Variable & Mean & SD & SF & PF & GR & C & OSB \\
\hline SF & 3.94 & .828 & 1 & & & & \\
\hline PF & 4.43 & .698 & $.526^{* *}$ & 1 & & & \\
\hline GR & 3.70 & .709 & $.387^{* *}$ & $.458^{* *}$ & 1 & & \\
\hline C & 4.10 & .450 & $.268^{* *}$ & $.372^{* *}$ & $.655^{* *}$ & 1 & \\
\hline OSB & 4.43 & .384 & $.831^{* *}$ & $.482^{* *}$ & $.675^{* *}$ & $.572^{* *}$ & 1 \\
\hline
\end{tabular}

Note: ${ }^{* * *} \mathrm{P}<.01 ; \mathrm{SD}=$ standard deviation; $\mathrm{SF}=$ social risk; $\mathrm{PF}=$ psychological factors; $\mathrm{GR}=$ government role; $\mathrm{C}=$ culture; OSB= online shopping behavior

\section{F. Hypothesis Testing}

Social risk, psychological factors, government role, culture, online shopping behavior 


\section{G. Structure Equation Modelling (Direct Effects)}

Table 3: Standardized estimates of direct effects

\begin{tabular}{|c|c|c|c|c|c|}
\hline $\begin{array}{c}\text { Indication of } \\
\text { relationship of } \\
\text { constructs }\end{array}$ & $\begin{array}{c}\text { Standardize } \\
\text { estimate }\end{array}$ & S.E & C.R & P-value & Results \\
\hline SR ------> OSB & -0.134 & 0.052 & -3.322 & $.000^{* * *}$ & Significant \\
\hline PF -----> OSB & -0.117 & 0.063 & -2.987 & $.000^{* * *}$ & Significant \\
\hline GR -----> OSB & 0.093 & 0.051 & 3.311 & $.000^{* * *}$ & Significant \\
\hline CR -----> OSB & 0.214 & 0.048 & 4.281 & $.000^{* * *}$ & Significant \\
\hline
\end{tabular}

Note: Level of significance 0.05

In above Table 3 show that social risk is negative and significant influence on online shopping behavior $(\beta=-0.134 ; \mathrm{t}$-value $=-3.322 ; \mathrm{p}<.05)$ and our hypotheses $\mathrm{H}_{1}$ accepted. It demonstrates that social risk significantly decreases online shopping behavior. Government role has significantly and positively impact on online shopping behavior $(\beta=0.093$; $\mathrm{t}$-value $=$ $3.311 ; \mathrm{p}<.05)$ and hypotheses $\mathrm{H}_{3}$ supported. It means that government role enhances the online shopping behavior of a consumer by giving assurance that his or her transaction secure and no worry in the stolen of money. Moreover, psychological factors are significant and negative influence on online shopping behavior $(\beta=-0.117$; $\mathrm{t}$-value $=-2.987 ; \mathrm{p}<.05)$ and our hypotheses $\mathrm{H}_{4}$ accepted. Meanwhile, culture has significant and positive influence on online shopping behavior $(\beta=0.214$; $\mathrm{t}$-value $=4.281 ; \mathrm{p}<.05)$ and accepted our hypotheses $\mathrm{H}_{5}$.

\section{H. Testing moderator hypothesis and results}

In the above section, discuss four direct relationships between social risk, psychological factors, government role, culture, and online shopping behavior. In this section, discusses the moderating role of culture between social risk and online shopping behavior. According to Holmbeck (1997), an interaction term is required to measure the effect of moderating variable (culture) between the independent variable (social risk) and the dependent variable (online shopping behavior). To test moderation hypotheses, this research develops a separate mode that consists of one independent variable, one dependent variable, and one moderating variable to determine the influence of standardized moderating scores. In the current research, SmartPLS 3.0 used to test moderating hypotheses and via this process online shopping behavior was expressed on social risk, moderating variable culture and the interaction term. Furthermore, the interaction term comes to multiply the scores that get from social risk and culture. The standard value of these variables was used that recommended (Aiken, West, \& Reno, 1991) in avoiding the Multicollinearity problem. By doing this 
Pakistan Journal of Humanities and Social Sciences, 7(1), 2019

significant correlation between variables and interaction term did not make any kind of problem in testing the moderating variable (Bahar Ozdogan \& Hakan Altintas, 2010).

\section{Moderator: Social media}

In current research examine the moderating influence of culture between the association of social risk and online shopping behavior. Below table 4 elaborates the hypotheses testing results of the cultural influence between social risk and online shopping behavior. In SmartPLS 3.0 during SEM analysis moderation effect exists when two conditions fulfill such as p-value less than 0.05 or t-value of interaction effect at least 1.96 (Hair et al., 2011). To test moderation effect of culture, all constructs including (standardized social risk), moderating variable (standardized culture), and interaction term (social riskstandardized score $\mathrm{x}$ culture standardized score) were regressed on online shopping behavior. Moderation between independent and dependent relationship exists when independent variable to dependent variable significant, moderating variable to dependent variable significant, and independent variable $\mathrm{x}$ moderating variable (interaction term) to dependent variable significant. Below table 4 shows that all three criteria fulfill and our hypotheses $\mathrm{H}_{2}$ accepted.

Table 4: Regression

\begin{tabular}{|c|c|c|c|c|c|}
\hline Hypotheses & Model Constructs & Estimate & S.E & P-value & Results \\
\hline & SF ----> OSB & 0.129 & 0.050 & 0.002 & \\
$\mathrm{H}_{2}$ & CR ----> OSB & 0.198 & 0.051 & 0.001 & Supported \\
& SF*CR (interaction) ---> & 0.136 & 0.057 & 0.002 & \\
\hline
\end{tabular}

\section{Discussion}

The purpose of this study is to determine the influence of social risk, psychological factors, and government role on online shopping behavior. Meanwhile, the objective of this research is to examine the moderating role of culture between social risk and online shopping behavior. Results revealed that social risk have a negative and significant impact on online shopping behavior and our hypotheses $\mathrm{H}_{1}$ accepted. Social risk reduces online shopping that supports (Aijaz \& Butt, 2009; Nasir, Wu, Yago, \& Li, 2015). Meanwhile, government role has a positive and significant influence on online shopping behavior and our hypotheses $\mathrm{H}_{3}$ supported. The findings are consistent with the findings of (Akhlaq \& Ahmed, 2015). Moreover, psychological factors have a significant and negative influence on online shopping behavior and our hypotheses $\mathrm{H}_{4}$ accepted. Psychological factors reduce online shopping that 
supports (Almousa, 2014; Y.-H. Chen et al., 2010). Additionally, culture significantly and positively moderates the relationship between social risk and online shopping behavior and $\mathrm{H}_{2}$ supported.

\section{A. Limitations and Recommendations}

Current research covers lots of things but still, there are some limitations that should be covered in future studies. First, this study collects data only from two cities in Pakistan and not covers other cities that why the findings of this research not generalized to other countries. Second current study distributes questionnaire among 130 respondents as the sample size is too small and this can increase in future research. Third, due to financial constraints and time limitations this research use three independent constructs and this can be increased in future studies. However, some other variables can be used in future research as an independent variable such as financial risk, product risk, privacy risk, convenience risk, electronic word of mouth, brand association, advertising factors, and perceived quality with online shopping behavior. Future research should be held in some other developing countries as well as in developed countries with financial risk, product risk, privacy risk, convenience risk, electronic word of mouth, brand association, advertising factors, perceived quality and online shopping behavior. Future studies in the field of online shopping behavior can use the theory of planned behavior and social exchange theory to build a theoretical framework. Future studies also use culture, trust, subjective norm, descriptive norms as moderating variable with online shopping behavior.

\section{Conclusion}

This study conducted to examine the impact of social risk, government role, and psychological factors on online shopping behavior in Pakistani environment. Current research contributes a lot in the literature of social risk, psychological factors, government role, culture, and online shopping behavior. This study overcomes some of the issues like social risk, psychological factors, government role, and culture that have impact on online shopping behavior of consumers. The main purpose of this research is to test hypotheses that we developed in the upper section and support on the association between social risk, psychological factors, government role, culture, and online shopping behavior. Findings elucidated that social risk and psychological factors have a negative and significant influence on online shopping behavior. Despite this, government role and culture has a significant but positive influence on online shopping behavior. Findings revealed that culture moderates the relationship between social risk and online shopping behavior. 


\section{Appendix: Scale}

\section{Social Risk}

1. The purchased product may result in disapproval by family.

2. Online shopping may affect the image of the people around me.

3. Online products may not be recognized by relatives or friends.

4. Online shopping may make others reduce my evaluation.

\section{Psychological Risk}

1. I cannot trust the online company.

2. I fear that the apparel will not be delivered appropriately.

3. I could be frustrated if I am dissatisfied with the quality of the product.

4. I may get addicted to online shopping.

\section{Government Role}

1. I think the government should help recycle discarded appliances.

2. I think the government is responsible for promoting regulations of environmental protection against certain appliances.

3. I think the government should enforce the control of environmental pollution and waste from green products.

4. I think the government should take more responsibility for environmental protection.

5. I think the government should request consumers to learn knowledge about environmental protection.

\section{Culture}

1. Parents and children must stay together as much as possible.

2. Before making a decision, I consult with most members of my family and many friends.

3. It is important to me that I respect the decision made by my group.

4. Family members should stick together, no matter what sacrifices are required.

5. I respect the opinion reached by the majority of my group.

\section{Online shopping behavior}

1. Using Internet for online shopping is easy

2. I shop online as I do not have to leave home for shopping

3. I shop online as I can get detailed product information online

4. I shop online as I get broader selection of products online

5. Online shopping gives facility of easy price comparison

6. I shop online as I can take as much time as I want to decide

7. I find online shopping compatible with my life-style

8. I use online shopping for buying products which are otherwise not easily available in the nearby market or are unique (new) 


\section{References}

Adnan, H. (2014). An analysis of the factors affecting online purchasing behavior of Pakistani consumers. International Journal of Marketing Studies, 6(5), 133.

Aijaz, H., \& Butt, F. S. (2009). BARRIERS IN THE DEVELOPMENT OF ELECTRONIC COMMERCE: A STUDY OF PAKISTANI ENVIORNMENT.

Aiken, L. S., West, S. G., \& Reno, R. R. (1991). Multiple regression: Testing and interpreting interactions: Sage.

Akhlaq, A., \& Ahmed, E. (2015). Digital commerce in emerging economies: Factors associated with online shopping intentions in Pakistan. International Journal of Emerging Markets, 10(4), 634-647.

Almousa, M. (2011). Perceived Risk in Apparel Online Shopping: A Multi Dimensional Perspective/LE RISQUE PERÇU DANS DES ACHATS EN LIGNE D'HABILLEMENT: UNE PERSPECTIVE DE DIMENSIONNELLE MULTIPLE. Canadian Social Science, 7(2), 23.

Almousa, M. (2014). The influence of risk perception in online purchasing behavior: examination of an early-stage online market. International Review of Management and Business Research, 3(2), 779.

Amin, S., \& Mahasan, S. (2014). Relationship between consumers per-ceived risks and consumer trust: a study of sainsbury store. Middle East J Sci Res, 19(19), 647-655.

Armstrong, G., Adam, S., Denize, S., \& Kotler, P. (2014). Principles of marketing: Pearson Australia.

Bahar Ozdogan, F., \& Hakan Altintas, M. (2010). Parent-adolescent interaction and the family's effect on adolescent TV skepticism: An empirical analysis with Turkish consumers. Young Consumers, 11(1), 24-35.

Bhatti, A. (2018). Consumer Purchase Intention Effect on Online Shopping Behavior with the Moderating Role of Attitude. International Journal of Academic Management Science Research (IJAMSR), 2(7), 44-50.

Bhatti, A., Saad, S., \& Gbadebo, S. M. (2018). Convenience Risk, Product Risk, and Perceived Risk Influence on Online Shopping: Moderating Effect of Attitude. Science Arena Publications International journal of Business Management, 3(2), 1-11.

Bhukya, R., \& Singh, S. (2015). The effect of perceived risk dimensions on purchase intention: An empirical evidence from Indian private labels market. American Journal of Business, 30(4), 218-230.

Candra, R. M., \& Iahad, N. A. (2013). Analysis of Consumer Risk Perception on Online Auction Features. Universiti Teknologi Malaysia.

Chen, C.-C., Chen, C.-W., \& Tung, Y.-C. (2018). Exploring the Consumer Behavior of Intention to Purchase Green Products in Belt and Road Countries: An Empirical Analysis. Sustainability, 10(3), 854.

Chen, Y.-H., Hsu, I.-C., \& Lin, C.-C. (2010). Website attributes that increase consumer purchase intention: A conjoint analysis. Journal of Business Research, 63(9), 10071014.

Hair, J. F., Ringle, C. M., \& Sarstedt, M. (2011). PLS-SEM: Indeed a silver bullet. Journal of Marketing theory and Practice, 19(2), 139-152.

Holmbeck, G. N. (1997). Toward terminological, conceptual, and statistical clarity in the study of mediators and moderators: Examples from the child-clinical and pediatric psychology literatures. Journal of consulting and clinical psychology, 65(4), 599.

Kanoti, R. W. K. (2017). Analysis of factors influencing adoption of online shopping-A Study of university students in Nairobi County. Strathmore University. 
Pakistan Journal of Humanities and Social Sciences, 7(1), 2019

Khan-SZABIST, S. H., \& Arshad-SZABIST, S. Z. (2010). Why E-Commerce Remains Unsuccessful in Pakistan?

Khan, S. H., \& Arshad, M. Z. (2010). Why E-Commerce Remains Unsuccessful in Pakistan?

Kotler, P., \& Armstrong, G. (2010). Principles of marketing: Pearson education.

Kotler, P., \& Keller, K. L. (2006). Identifying market segments and targets. Marketing management, 12th edition, Pearson Education Singapore, 234.

Lee, H.-J., \& Huddleston, P. T. (2009). An investigation of the relationships among domainspecific innovativeness, overall perceived risk and online purchase behavior. International Journal of Electronic Marketing and Retailing, 3(1), 1-4.

leyiaro, L. (2015). Factors Influencing Consumer Online Buying Behavior In A Project Based Company. A Case Of Geothermal Development Company. .

Li, N., \& Zhang, P. (2002). Consumer online shopping attitudes and behavior: An assessment of research. Former Departments, Centers, Institutes and Projects, 57.

Little, W., Vyain, S., Scaramuzzo, G., Cody-Rydzewski, S., Griffiths, H., Strayer, E., \& Keirns, N. (2012). Introduction to Sociology-1st Canadian edition. BC Open Textbook project.

Masoud, E. Y. (2013). The effect of perceived risk on online shopping in Jordan. European Journal of Business and Management, 5(6), 76-87.

Meyers, L. S., Gamst, G., \& Guarino, A. J. (2016). Applied multivariate research: Design and interpretation: Sage publications.

Nasir, M. A., Wu, J., Yago, M., \& Li, H. (2015). Influence of psychographics and risk perception on internet banking adoption: Current state of affairs in Britain. International Journal of Economics and Financial Issues, 5(2).

Nazir, S., Tayyab, A., Sajid, A., Rashid, H., \& Javed, I. (2012). How Online Shopping Is Affecting Consumers Buying Behavior in Pakistan? International Journal of Computer Science Issues, 9(3), 486-495.

Nunnally, J. (1978). Psychometric Theory (2nd Edit.) McGraw-Hill. Hillsdale, NJ.

Oluyinka, S., Shamsuddin, A., Wahab, E., Ajagbe, M. A., \& Enegbuma, W. I. (2013). A study of electronic commerce adoption factors in Nigeria. International Journal of Information Systems and Change Management, 6(4), 293-315.

Park, H., Rehg, M. T., \& Lee, D. (2005). The influence of Confucian ethics and collectivism on whistleblowing intentions: A study of South Korean public employees. Journal of Business Ethics, 58(4), 387-403.

Popli, A., \& Mishra, S. (2015). Factors of Perceived Risk Affecting Online Purchase Decisions of Consumers. Pacific Business Review International, 8 (2), 49, 58.

Qureshi, H. A., Fatima, R., \& Sarwar, A. (2014). BARRIERS TO ADOPTION OF ONLINE SHOPPING IN PAKISTAN. Science International, 26(3).

Rani, P. (2014). Factors influencing consumer behavior. International journal of current research and academic review, 2(9), 52-61.

Ricciuto, L., Tarasuk, V., \& Yatchew, A. (2006). Socio-demographic influences on food purchasing among Canadian households. European Journal of Clinical Nutrition, 60(6), 778.

Rind, M., Hyder, M., Saand, A. S., Alzabi, T., Nawaz, H., \& Ujan, I. (2017). Impact Investigation of Perceived Cost and Perceived Risk in Mobile Commerce: Analytical Study of Pakistan. IJCSNS, 17(11), 124.

Scouting/BSA. (21 March 2018). Scouting/BSA/Citizenship in the Nation Merit Badge. from https://en.wikibooks.org/wiki/Scouting/BSA/Citizenship_in_the_Nation_Merit_Badg e 
Shahid, J. (March 10, 2016). Govt urged to increase spending on R\&D. from https://www.dawn.com/news/1244723

Tanner, J., \& Raymond, M. (2012). Marketing principles. Houston: Flat World Education.

Yusufzai, A. (2018). Literacy Rate in Pakistan Drops by 2\% in 2016-17. from https://propakistani.pk/2017/05/26/literacy-rate-pakistan-drops-2-2016-17/

Zhang, L., Tan, W., Xu, Y., \& Tan, G. (2012). Dimensions of consumers' perceived risk and their influences on online consumers' purchasing behavior. Communications in Information Science and Management Engineering, 2(7). 